\title{
Fostering Entrepreneurship Education in Africa: Presenting the Orchestration of a Pan-African University Alliance
}

\author{
Alisa Sydow, Benedetto Lorenzo Cannatelli, Alessandro Giudici, Sam \\ Kamuriwo, Mario Molteni \\ alisa.sydow@unicatt.it; benedetto.cannatelli@unicatt.it; alessandro.giudici.2@city.ac.uk \\ Università Cattolica del Sacro Cuore, Via Necchi 7, Milan (Italy); CASS Business School, Buhill Row 106, London
}

\begin{abstract}
Taking the salient case of an Italian Foundation that promoted a Pan-African university alliance for entrepreneurship education, we conducted a field study based on interviews and observation for a period of seven years. The aim was to understand how to overcome challenges that arise when fostering entrepreneurship education programs (EEP) by orchestrating an inter-organizational network in Africa. Our study revealed that proximity and the presence on the field play a strategic and crucial role in orchestrating an entrepreneurial eco-system in a context shaped by resource scarcity and solid societal as well as economic problems. We contribute to scholarly and practitioner understandings of how to establish effectively EEPs by orchestrating entrepreneurial eco-systems in Africa.
\end{abstract}

Keywords: Entrepreneurship Education, Network Orchestration, Africa

\section{Introduction}

Over the last decades, entrepreneurship has become an important economic and social topic as well as an oftenresearched subject (Fayolle and Gailly, 2008). Accordingly, entrepreneurship education has gained increasing attention from scholars (Harris \& Gibson, 2008; Mitra \& Matlay, 2004). In this vein, scholars began to focuson how to design an effective entrepreneurship education programs (EEP), primarily embracing studies based on competence models in order to understand which skills and actions are required to effectively deliver entrepreneurship education (Gielnik et al., 2015, Nabi et al., 2015).

In this scenario, EEPs has been recognized as one of the instruments for fostering entrepreneurial attitudes, intentions, and competences (need ref from below). This view - indeed - has led to a dramatic rise in the number and status of EPPs offered by colleges and universities worldwide (Kuratko 2005; Matlay 2005). Although education is widely accepted as a leading instrument for promoting economic growth, it might get stunted and challenged in environments in which the foundational infrastructure for the conduct of business is not sufficient to stimulate business formation and growth (Arrow, 1969; Khanna \& Palepu, 1997). Hence, emerging markets such as Africa as an entire continent - present rich settings for studying both voids in commercial institutions (Hoskisson et al., 2000) and their resulting challenges for entrepreneurship education. By the absence of basic resources and cohesive industrial structure or market infrastructure for new venture creations, entrepreneurs need more support than training and education in theoretical content (George \& Prabhu, 2000). 
To illuminate those issues and to foster entrepreneurship education, we need to focus on orchestrating entrepreneurial eco-systems. However, recent studies have been limited towards studying single units of entrepreneurship training instead of looking at entire programs of study and the development of their interorganizational network. For this reason, we want to catch-up the on-going discussion regarding competence models in entrepreneurship education by extending our perspective towards a complete course of entrepreneurship studies and its orchestration of inter-organizational networks in Africa. In this paper - by proposing a field study on the basis of direct participation and observation - we aim to contribute to entrepreneurship education literature by explaining how to overcome challenges that arise when fostering EEP by orchestrating an inter-organizational network in Africa. To this aim, we based our study on the case of a Pan-African university alliance which is composed of seven African universities offering a MBA in Entrepreneurship in collaboration with an Italian foundation. This network of African universities presents a salient case - promising to allow new insights to emerge more sharply. The paper proceeds as follows: we first introduce extant literature on entrepreneurship education and its focus on competence models and action-based trainings. Second, we provide a detailed description of the studied case and the way we have collected data which has been further analyzed. Third, we present our main findings by advancing a set of recommendations. Finally, we discuss implications as well as limitations of the paper and offer indications for further research.

\section{Method}

This research draws on a case study of E4impact, an Italy-based foundation supporting the creation as well as the growth of new ventures in developing countries by means of entrepreneurial training. The initiative has been launched in 2010 as a single unit of Università Cattolica del Sacro Cuore, then evolved into an academic spin-off, named "E4impact Foundation" - in 2015 by including some major Italian business actors such as Securfin, Mapei, Salini-Impregilo, Always Africa Association, and Università Cattolica del Sacro Cuore itself. Our analysis is confined to the launch and growth phase of E4impact, between 2010 and 2017, when the implementation of the program and the governance of the network experienced significant turbulence. The unique configuration of our research context - thus - provide a case with "rare" qualities (Eisenhardt, 1989) and a powerful "talking pig" (Sikkelkow, 2007) to illuminate how to overcome challenges that arise when fostering EEP by orchestrating an inter-organizational network in Africa.

\subsection{Data collection}

Our data collection started in 2010 and has been continuously conducted until 2017. Hence, we collected a significant amount of both archival and primary data, as summarized in Table 1.

Table 1: Sources of Data Collection

\begin{tabular}{cccccc}
\hline \multicolumn{5}{c}{ Sources } \\
\hline Year & $\begin{array}{c}\text { Interviews } \\
\text { (\# of min) }\end{array}$ & $\begin{array}{c}\text { Field } \\
\text { Observation } \\
\text { (\# of hrs) }\end{array}$ & $\begin{array}{c}\text { Documents } \\
\text { (\# of pages) }\end{array}$ & $\begin{array}{c}\text { Articles } \\
\text { (\# of pages) }\end{array}$ & Website \\
\hline 2010 & 200 & 180 & 90 & 38 & $\checkmark$ \\
2011 & 89 & 66 & 120 & 16 & $\checkmark$
\end{tabular}




$\begin{array}{lccccc}2012 & 170 & 238 & 115 & 24 & \checkmark \\ 2013 & 234 & 377 & 170 & 9 & \checkmark \\ 2014 & 314 & 425 & 200 & 13 & \checkmark \\ 2015 & 97 & 130 & 240 & 22 & \checkmark \\ 2016 & 90 & 160 & 290 & 9 & \checkmark \\ 2017 & 220 & 140 & 260 & 17 & \checkmark\end{array}$

We conducted 1,511 minutes of interviews, 1,716 hours of observations, 1,485 pages of business documents, and 148 articles. Interviews lasted between 30 and 90 minutes and were all digitally recorded and transcribed verbatim. To minimize confirmatory biases (Eisenhardt \& Graebner, 2007), the number of interviews conducted have been equally distributed among the authors. We jointly cross-checked and challenged the primary evidence as it emerged. Given our reliance on retrospective interviews, similar to Byrne and Shepherd (2015; see also Chandler \& Lyon, 2001; Perry, Chandler, \& Markova, 2011), we proactively tried to counterbalance the risk of recall bias (Eisenhower, Mathiowetz, \& Morganstein, 2004) by triangulating our evidence with other data sources, including archival material and direct observation (Eisenhardt, 1989). We had the opportunity to attend many internal meetings and events, as two authors took actively part in the process and management of the E4impact Foundation.

\subsection{Data Analysis}

We integrate qualitative analysis of interview and observational data with structural analysis of the developing network. This enables us to explore the actions of the network orchestrator, namely the E4impact Foundation, how these actions were adjusted in response to the outlined dilemmas, and with what consequences for the network's evolution. We followed three key steps for the data analysis. First, we created an event-history database founded on the chronological codification of our interviews, field notes and archival data such as articles and business documents. Second, we coded our primary and secondary data through several cycles of comparisons between data and theory until we obtained "meaningful conceptual categories" (Eisenhardt, 1989; Tracey \& Jarvis, 2007). Tasks were divided among the authors to minimize reliability issues (Larsson, 1993). In the last step, we refined and then, integrated our findings into the foundation's actions and network outcomes by different developmental network phases based on the framework of the scholars Paquin and Howard-Grenville (2013). Our final findings are presented in the next section. To begin, it is helpful to contextualize the research with a brief account of the history of E4impact Foundation.

\subsection{Research Context: E4impact Foundation}

In 2005 the Congregation for the Evangelization of Peoples (Propaganda Fide) of the Roman Catholic Church, in the person of Cardinal Crescenzo Sepe, desired to offer a formation program which could contribute to the economic development of the African continent. The idea was to offer in Castel Gandolfo, Italy a residential master for Africa's future Catholic business managers, destined to play a significant role in the African Church and society. The initiative was successful, but after a few years two major problems became evident. First, the economic crisis made it increasingly difficult to offer scholarships. Second, above all, many young Africans, while carefully selected for their dedication to their native countries, often attempted to create a career for themselves in Europe, contributing to boosting rather than inhibiting the continent's brain drain. As a consequence, the program changed to no African students in Italy, but the Master in Africa and thus, E4impact was launched in 2010 by ALTIS - Graduate School of Business and Society of Università Cattolica del Sacro Cuore (Milan, Italy). The idea was to cease operating in isolation, but to partner with a local university, who would eventually become key 
actors in the delivery of the program. The main approach of the program is reflected in the following motto: "Not for job seekers, but for job creators". The starting point for this program was in 2010 with a partnership with Tangaza College, a constituent college of the Catholic University of East Africa in Nairobi, Kenya. During the subsequent years, the program has been further developed and has been expanded to Ghana, Sierra Leone, Uganda, Ivory Coast, Senegal and Ethiopia with approximately 544 entrepreneurs trained (see Figure 1 for more information about the development).

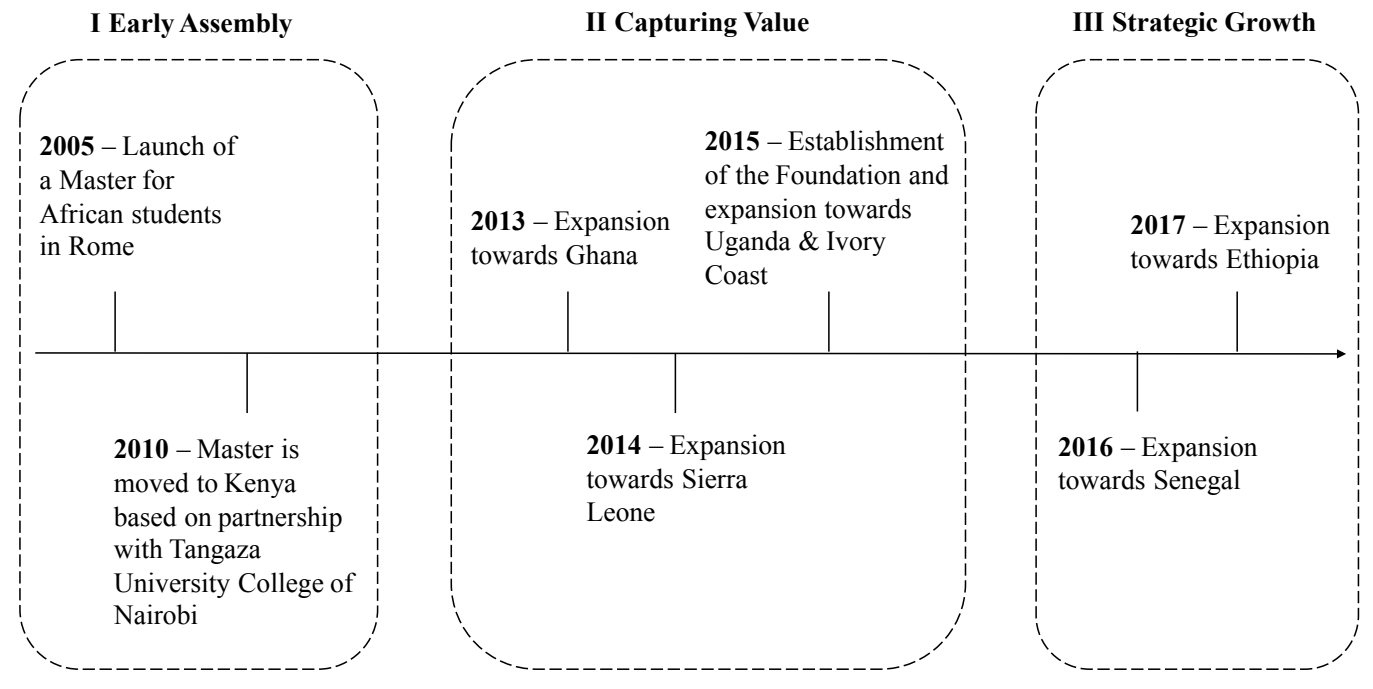

Figure 1: Timeline of Foundation

\section{Findings}

The findings section is organized according to the structure presented in Figure 1 which reveals three principle stages of the evolution of a Pan-African university alliance driven by E4impact Foundation. We use extensive data extracts to "describe the case in sufficient descriptive narrative so that readers can experience these happening vicariously and draw their own conclusions" (Stake, 1995:450).

Table 2: Key Developmental Network Phase (based on Paquin \& Howard-Grenville, 2013)

\begin{tabular}{|c|c|c|c|}
\hline & Phase 1: Early Assembly & Phase 2: Capturing Value & Phase 3: Strategic Growth \\
\hline $\begin{array}{l}\text { E4impact's key } \\
\text { dilemmas by } \\
\text { phase }\end{array}$ & $\begin{array}{l}\text { Lack of experience and } \\
\text { knowledge of the setting } \\
\text { - Understanding the needs of } \\
\text { local entrepreneurs }\end{array}$ & $\begin{array}{l}\text { - } \\
\text { Setting-up an org. structure \& } \\
\text { org. culture } \\
\text { - } \quad \text { Lack of local key players such } \\
\text { as: incubators and accelerators }\end{array}$ & $\begin{array}{l}\text { - Control \& Coordination of } \\
\text { increasing network } \\
\text { members } \\
\text { - } \quad \text { Quality management }\end{array}$ \\
\hline
\end{tabular}

Orchestrator's Approach and Resources 


\begin{tabular}{|c|c|c|c|}
\hline Main actions & $\begin{array}{l}\text { - } \quad \text { Partnership between E4impact } \\
\text { \& Tangaza College } \\
\text { - } \quad \text { Launch of Master Program }\end{array}$ & $\begin{array}{ll}\text { - } & \text { Redesign of Master Program \& } \\
\text { internal structure } \\
\text { - } & \text { Set-up partnerships with local } \\
& \text { organizations }\end{array}$ & $\begin{array}{l}\text { - Strengthen partnerships } \\
\text { with local organizations } \\
\text { - Launch of multiple } \\
\text { products }\end{array}$ \\
\hline $\begin{array}{l}\text { Resources } \\
\text { available to } \\
\text { leverage for } \\
\text { network assembly }\end{array}$ & $\begin{array}{ll}\text { - } & \text { Qualified professors \& } \\
\text { employees from Italy } \\
\text { - } & \text { Support of Catholic Church to } \\
\text { increase awareness }\end{array}$ & $\begin{array}{l}\text { - Local Business Coach } \\
\text { - Local manager to build up the } \\
\text { master program \& local } \\
\text { partnerships }\end{array}$ & $\begin{array}{l}\text { - Local professors and } \\
\text { coaches } \\
\text { - } \quad \text { Experience \& know-how }\end{array}$ \\
\hline
\end{tabular}

\section{Network Value}

\begin{tabular}{|c|c|c|c|}
\hline $\begin{array}{l}\text { Perception of } \\
\text { network value by } \\
\text { participants }\end{array}$ & $\begin{array}{l}\text { - E4impact: Integration into the } \\
\text { setting } \\
\text { - } \quad \text { Tangaza College: Prestige due } \\
\text { to cooperation } \\
\text { - Students: High Quality Master } \\
\text { Program }\end{array}$ & $\begin{array}{l}\text { E4impact: Gain in expertise \& } \\
\text { experience } \\
\text { - } \\
\text { African Partner Universities \& } \\
\text { Students: Access to high-quality } \\
\text { training, incubators \& } \\
\text { accelerators }\end{array}$ & $\begin{array}{l}\text { - E4impact: high credibility } \\
\text { as orchestrator } \\
\text { - African Partner } \\
\text { Universities \& Students: } \\
\text { access to key resources, } \\
\text { inter. partners \& expertise }\end{array}$ \\
\hline
\end{tabular}

Outcomes

\begin{tabular}{l|l|l|l}
\hline $\begin{array}{l}\text { Changes in } \\
\text { network structure }\end{array}$ & $\bullet \quad$ First formalized partnership & $\bullet \begin{array}{l}\text { Increase in the number of } \\
\text { network members }\end{array}$ & $\begin{array}{l}\text { Clear role of network } \\
\text { members } \\
\text { Interest of Italian firms }\end{array}$ \\
$\begin{array}{l}\text { Results that } \\
\text { trigger shift to } \\
\text { next phase }\end{array}$ & $\begin{array}{l}\text { Misfit of student's needs \& } \\
\text { program structure } \\
\text { Cultural discrepancies between } \\
\text { participants }\end{array}$ & $\bullet \begin{array}{l}\text { Identification of a scalable } \\
\text { master program } \\
\text { Acceptation of E4impact as key } \\
\text { relational broker }\end{array}$ & $\begin{array}{l}\text { Accumulation or } \\
\text { orchestrator's resources \& } \\
\text { expertise }\end{array}$ \\
& & $\begin{array}{l}\text { Growing Interest of } \\
\text { European firms to connect }\end{array}$
\end{tabular}

\subsection{Early Assembly}

After the launch of the Master for African students in Rome in 2005, it has become evident that the program has generated an increase in brain drain as many students have decided to start their individual professional carriers in Europe. As a consequence, E4impact has established in 2010 a partnership with Tangaza College in Nairobi, Kenya. Based on the previous experience both parties were open to find an agreement to fix their cooperation. In order to set up those agreements, the Italian initiative decided to hire an employee being experienced in projects with Africa. This employee described the process as "very time-consuming and exhausting. When I arrived, there was just a very informal basic agreement on the cooperation without any details and clear regulations. ” 
He has spent up to six months in Nairobi in order to specify and establish the partnership with Tangaza College. At the same time, it was necessary to set up the content and structure of the program which has been mainly done by the Italian university and its specialized and experienced professors. The knowledge and experience inherent by the Italian professors needed to get passed to the local professors in order to empower them to teach the content of the master. Hence, in the first two editions, the Italian university has focused on building capacity by training local professors to ensure the requested knowledge transfer to the students. In this first assembly, the man value of the partnership for E4impact lies in the integration into the local context. Due to cultural differences the local experience and know-how of Tangaza College was important in order to cease working in isolation. First, a misfit of student's needs and the program structure as it has been too intense in terms of class hours as most of the students were not from Nairobi. Thus, they could not attend some classes due to the fact that they needed to go back for work and to support the family. One of the employees has stressed this observation by the following comment:

"I remember one week, in which there were only like half of the students present in class. And it was in the right in the middle of the program. This was the moment in which we started to ask ourselves "why?".

Furthermore, a lack in basic computer- and management skills among the students has become evident in the course of the first two editions of the master. Second, strong cultural discrepancies have been emerged between various groups of participants as outlined in the illustration of one employee.

"Another problem we had - always at the cultural level - was with the local partners. The professors were divided into Italian ones and local ones. Unfortunately, there was no alignment between them. The way they taught was very different. For example, the concept of sustainability was perceived and explained in a very different manner. Moreover, we launched the program shortly after the social problems attached to the elections in Kenya. So we were in the middle of turbulence between the two parties. Thus, there were still strong tensions between the different tribes. There were teachers with different ethnic groups and so the tensions were felt every day."

\subsection{Capturing Value}

In the second phase, which is basically shaped by the establishment of the E4impact Foundation in 2015, the focus lied on the process of setting-up a network structure, as well as, an internal structure to link and coordinate the different network members. Working side by side with the Kenyan partner an innovative design emerged: an executive formula with only 40 days in the classroom to allow the entrepreneur to continue working; distance learning modules which take advantage of the growing penetration of the internet in Africa; a full time, on staff, business coach who provides individual guidance to each entrepreneur. One of the employees of E4impact has described it in the following way:

"Basically, our idea was not to offer a standard MBA which they can do at several universities, but to design a hybrid model, namely a mix between a MBA and an accelerator due to the specific needs of the students."

The effectiveness of the new formula led to interest from other African Universities. In a short period of time and without actively promoting the program, the MBA was also launched in Ghana, and Sierra. Consequently, the orchestrator, E4impact, was obliged to adopt its internal structure according to the occurring changes in the network. From 2010 until 2013, the internal structure of E4impact was designed as one person in charge from 
E4impact for one specific country. One main benefit was the level of specification as it was possible to customize the offers directly to the needs of each university. By adding more university this internal structure has become inefficient. Thus, E4impact has - after the establishment of the foundation - integrated the role of area managers who are in charge of more countries being placed in a certain geographical area. Those area managers are - on the one hand - in direct contact with the various partner universities and - on the other hand - they need to report to the central manager of the master. In this vein, synergy effects based on an approach of centralization has been generated. The enrollment process, training of local professors, and the design of the academic calendar have been standardized by the E4impact Foundation. Marketing though, has been identified as an area which requires customization as the way and style of communication varies strongly among the partner universities. One of the area managers has described the challenge as

"Complexity, the real difficulty is making the project scalable. Complexity is multiplied. You learn from one program to another. But there are many local problems that must be understood and resolved locally. So, you cannot handle it in a centralized way."

\subsection{Strategic Growth}

By integrating more universities, the complexity has increased. E4impact Foundation as the key orchestrator embodies the role of controlling and coordinating the various network members and more specifically, to establish the ties between different African universities. However, at the same time each launched program in different countries need to be managed and improved. "There are still a couple of things not really working well. For instance, the idea of the business coach is brilliant. Though the challenge is to find an appropriate person to perform this role. I have seen that some students, actually the best ones, decided to skip the coaching sessions as they do not perceive them as helpful and valuable."

This observation represents an emerging problem regarding the quality of the program and its offered services. A similar issue has been observed in the content and style of teaching done by local professors and their commitment to the job. E4impact Foundation struggles how to design an effective process of controlling and tracking the performance of local employees which is fortified by the distance between Italy and the African partner countries. This distance has been seen also as a motor for creating some misunderstanding in the communication and way of working between the orchestrator and some of the partner universities. As main element of the growth strategy, E4impact Foundation is planning to add not only new countries, but to integrate various products in its portfolio. Instead of focusing on the MBA in Global Business and Sustainability as a single product, the idea is to build upon this MBA and offer similar products customized by the identified needs of the local students.

\section{Conclusions}

By providing a rare examination of the discussed case, we extend entrepreneurship education research by looking not only at a single program but by analyzing the orchestration of an entrepreneurial eco-system in Africa based on the establishment of a Pan-African university alliance. In particular, we have divided the development into 
three main phases - namely - early assembly, capturing value and strategic growth. We found that a one of the main challenges at the beginning lies in finding an appropriate design of the master due to the specific needs of the students. Differences in the type of students and in the culture call for a hybrid design of the master - a fusion between a traditional MBA and an accelerator which represents the basic principles of competence models in entrepreneurship education (Kirkwood, Dwyer, \& Graz, 2014; Nabi et al., 2016). Students are required to take their real-life new ventures or business ideas and they need to develop them during the course of the master. Our findings have shown that enrollment processes, capacity building of professors and the design of the academic calendar are points which can be standardized. Whereas marketing and some administrative processes needs to be individually designed. In conclusion, we contribute to entrepreneurship education research by illustrating answers to the initial research question of how to overcome challenges that arise when fostering EEP by orchestrating an inter-organizational network in Africa to facilitate positive economic development.

\section{References}

[1] Arrow, K. J. 1969. Classificatory Notes on the Production and Transmission of Technological Knowledge, The American Economic Review, 59 (2), 29 - 35.

[2] Fayolle, A., \& Gailly, B. 2008. From craft to science: Teaching models and learning processes in entrepreneurship education, Journal of European Industrial Training, 32 (7), 569 - 593.

[3] George, G., \& Prabhu, G. N. 2000. Developmental Financial Institutions as Catalysts of Entrepreneurship in Emerging Economies, Academy of Management Review, 25 (3), 620 - 629.

[4] Gielnik, M. M., Frese, M., Kahara-Kawuki, A., Katono, I. W., Kyejjusa, S., \& Ngoma, M. 2015. Action and Action-Regulation in Entrepreneurship: Evaluating a Student Training for Promoting Entrepreneurship. Academy of Management Learning and Education, 14 (1), 69 - 94.

[5] Harris, M. L., \& Gibson, S. G. 2008. Examining the entrepreneurial attitudes of US business students, Education + Training, 50 (7), $568-581$.

[6] Hoskisson, R. E., Eden, L., Lau, C. M., \& Wright, M. 2000. Strategy in Emerging Economies, Academy of Management Journal, 43 (3), 249 - 267.

[7] Khanna, T., \& Palepu, K. 1997. Why focused strategies may be wrong for emerging markets, Harvard Business Review, 4, $41-48$.

[8] Kirkwood, J., Dwyer, K., \& Gray, B. 2014. Students' reflections on the value of an entrepreneurship education, The International Journal of Management Education, 12 (3), 307 - 316.

[9] Kuratko, D. F. 2005. The Emergence of Entrepreneurship Education: Development, Trends, and Challenges, Entrepreneurship Theory and Practice, 29 (5), 577 - 598.

[10] Matlay, H. 2005. Entrepreneurship education in UK business schools: conceptual, contextual and policy considerations, Journal of Small Business and Enterprise, 12 (4), 627 - 643.

[11] Mitra, J., \& Matlay, H. 2004. Entrepreneurial and Vocational Education and Training, Industry and Higher Education, 18 (1), $53-61$.

[12] Nabi, G., \& Linan, F. 2011. Graduate entrepreneurship in the developing world: intentions, education and development. Education + Training, 53 (5), 325 - 334.

[13] Paquin, R. L., \& Grenville-Howard, J. 2013. Blind Dates and Arranged Marriages: Longitudinal Processes of Network Orchestration, Organization Studies, 34 (11), 1623 - 1653. 